\title{
A Method for Detection of Trace Concentrations of Underivatized Amino Acid in Hydrothermal Fluids by Ion-Pairing Reversed-Phase UPLC-ESI-QTOF-MS
}

\author{
Cécile Konn ${ }^{1,3}{ }^{*}$, Jörgen Magnér ${ }^{2,4}$, Jean-Luc Charlou ${ }^{3}$, Nils G. Holm¹, Tomas Alsberg2 \\ ${ }^{1}$ Department of Geological Sciences, Stockholm University, SE-10691 Stockholm, Sweden \\ ${ }^{2}$ Department of Environmental Science and Analytical Chemistry (ACES), Stockholm University, SE-10691 \\ Stockholm, Sweden \\ ${ }^{3}$ Ifremer, Laboratoire de Géochimieet Métallogénie, F-29280 Plouzané, France \\ ${ }^{4}$ IVL Swedish Environmental Research Institute Ltd., SE-10031 Stockholm, Sweden \\ Email: ${ }^{*}$ cecile.konn@ifremer.fr
}

Received 16 January 2015; accepted 9 March 2015; published 12 March 2015

Copyright (C 2015 by authors and Scientific Research Publishing Inc.

This work is licensed under the Creative Commons Attribution International License (CC BY).

http://creativecommons.org/licenses/by/4.0/

(c) (i) Open Access

\section{Abstract}

Investigation of amino acids in hydrothermal systems is of prime importance for the understanding of geochemistry and microbiology of hydrothermal vents and plumes, for carbon and metals global cycles, for metabolism of some hydrothermal microorganisms and for the origin of life issue. Extensive theoretical and experimental work on amino acids behaviour in hydrothermal fluids has been done, conversely only few data exist on natural samples. Because each hydrothermal vent is unique, the more data we collect the better we will be able to address each of these questions. Usually amino acids in hydrothermal fluids have been measured by HPLC-FLD. The chromatographic separation was at least $26 \mathrm{~min}$ and up to $135 \mathrm{~min}$ and the required derivatization step may be time consuming, may use harmful chemicals and may be source of contamination. Alternatively, we describe here a method combining quickness $(4.5 \mathrm{~min})$, high resolution $(10,000)$, very low LOD (sub-ppb) and without derivatization. Characterisation and separation of 10 relevant proteinogenic underivatized amino acids was achieved by ion-pairing reversed-phase Ultrahigh Performance Liquid Chromatography-Electrospray Ionisation-Quadrupole Time of FlightMass Spectrometry (UPLC-ESI-QTOF-MS). Excellent linearity in the response was obtained for all amino acids with correlation coefficients $>0.9921$. This method was successfully applied to natural hydrothermal fluid samples from ultramafic-hosted vents of the Mid-Atlantic Ridge region. Results are consistent with the only 2 other studies published on ultramafic-hosted vents and complete the few available data.

\footnotetext{
${ }^{*}$ Corresponding author.
}

How to cite this paper: Konn, C., Magnér, J., Charlou, J.-L., Holm, N.G. and Alsberg, T. (2015) A Method for Detection of Trace Concentrations of Underivatized Amino Acid in Hydrothermal Fluids by Ion-Pairing Reversed-Phase UPLC-ESI-QTOFMS. American Journal of Analytical Chemistry, 6, 313-324. http://dx.doi.org/10.4236/ajac.2015.64030 
Keywords

Amino Acids, UPLC, Ion-Pairing, QTOF, Mass Spectrometry, Hydrothermal Fluids

\section{Introduction}

Excellent and comprehensive discussions on the origin, stability and thermodynamic properties of amino acids in hydrothermal fluids have already been published and we strongly urge the reader to refer to them. In order to introduce these essential references we will begin our introduction with a brief summary of major findings and ideas.

The study of amino acids in hydrothermal systems is gaining importance as they represent key compounds in many fields of hydrothermal research. 1) Hydrothermal fields appear favourable for prebiotic chemistry and of particular interest amino acids are the first building blocks for the emergence life e.g. [1]-[5]. Especially abiotic synthesis under the high reducing condition (elevated $\left[\mathrm{H}_{2}\right]$ ) found in ultramafic-hosted hydrothermal systems is supported by thermodynamics e.g. [6] [7], experimental e.g. [8] [[9] and references therein] and field data e.g. [10] [11]. Amino acids do occur in hydrothermal fluids and although the presence of a small fraction of abiogenic amino acids has not been excluded, the authors have claimed unanimously they were biogenic (microbial production) or thermogenic (organic matter degradation) [12]-[17]. The occurrence and persistence of amino acids in hydrothermal fluids likely depend on multiple parameters such as pressure, temperature, redox conditions, thermodynamics, kinetics, residence time and microbial activity. Extensive experimental work has been conducted to investigate the stability of amino acids under hydrothermal conditions, yet the conclusion is still unclear e.g. [18]-[21]. A consensus towards stability at short time scales seems to emerge. Notably this life time may be enhanced by mineral surfaces protection [22]. 2) Amino acid metabolism has recently been described as a major metabolic pathway in the deep subsurface biosphere [23]. 3) Amino acids may also reach the hydrothermal plume and thus sustain communities therein. 4) They constitute complexing agent for metals and thus may play a role in their bioavailability and transport through the ocean.

Amino acid analyses have been carried out for a long time, however their high polarity, low volatility and lack of a strong chromophore group result in strenuous separation and detection. For 60 years many analytical techniques have been developed and have broadened depending on the scientific, industrial and health research needs. One can indeed be interested in measuring the total amount of dissolved free amino acids (DFAA), in separating and identifying them, in quantifying each amino acid or in separating the $\mathrm{D}$ to the $\mathrm{L}$ forms. Besides, analytical instrumentation has become more and more accurate and efficient over the years leading to the possibility of identifying, quantifying and separating amino acids and configurations in a variety of matrices.

Main challenges in the analysis of amino acids in hydrothermal fluids are the complexity of the matrix which contains high concentrations of salts and metals [24] [25] and the trace concentrations of amino acids to be detected. Liquid Chromatography-Fluorescence Light Detector (FLD) has typically been used for separating and measuring amino acids in hydrothermal fluids [12]-[17]. Long chromatographic separation times of at least 25 $\min$ and up to $135 \mathrm{~min}$ were reported. Limits of detection (LOD), although they were $<10 \mathrm{nM}$ in most cases, ranged from 1 to $34 \mathrm{nM}$ depending on the amino acid and resulted in many non-detected amino acids. Finally, the method involves a derivatization step which may be a source of contamination, be time consuming, use harmful chemicals and create reagent interferences. Derivatization also means that the original sample is chemically modified, which, to our point of view, should be avoided when working on little known samples and systems. The need for a method that would be rapid, sensitive and without derivatization appeared of prime importance for the study of amino acids in hydrothermal fluids.

Analyses of underivatized amino acids are often carried out either by LC or ion chromatography (IC). We will compare various methods in terms of retention times and LOD based on the set of the 10 proteinaceous amino acids chosen for the present work. Analyses by IC with amperometric detection requires extremely long separation time (up to $50 \mathrm{~min}$ ) and results in too high LOD for our purpose [26] [27]. Özcan and Şenyuva [28] used HPLC-Atmospheric Pressure-Chemical Ionisation-MS and resulted in fast separation but rather low resolution and far too high LOD for our purpose (>100 nM). Many different detectors may be coupled to LC. The best results for different parameters were generally obtained with a MS detector; especially LOD were lowered but not 
sufficiently for trace analyses [29] [30]. LOD are typically improved by the use of tandem mass spectrometry (MS/MS) or Ultra-high Performance Liquid Chromatography (UPLC). HPLC-MS/MS appeared reasonably fast (5 - $15 \mathrm{~min}$ ) but LOD were still too high [31] [32]. Similar conditions (10 min, LOD $>10 \mathrm{nM}$ ) were obtained by Zhou et al. [33] who used UPLC with a triple quadrupole and a specific column. Elsewhere it has been reported that retention times and thus the response signal of underivatized amino acids could be improved on classic $\mathrm{C}_{18}$ column by an ion-pairing agent [34]-[36]. These pioneers in ion-pairing HPLC-ESI-MS/MS achieved separation in about $13 \mathrm{~min}$ and obtained LOD from 0.03 to $3 \mu \mathrm{M}$ depending on the amino acid. The technique was used later on but LOD were similar or not reported and retention times were higher [37] [38]. Adaptation of the original method to the current most efficient chromatographic instrument (UPLC) enhanced the analysis time down to $6.5 \mathrm{~min}$ [39]. Nevertheless the problem of high LOD remains. To the best of our knowledge and despite the extensive work published on the analyses of underivatized amino acids, a technique that would enable fast separation and detection of underivatized amino acids at trace concentration has not yet been clearly described and validated. The purpose of this paper is to describe a rapid, simple and sensitive method for the analyses of underivatized amino acids in hydrothermal fluids and present some results of natural samples as an illustration. Based on the methods of Piraud et al. [35] and Armstrong et al. [40], we report here the use of Ultrahigh Performance Liquid Chromatography-Electrospray Ionisation-Quadrupole Time of Flight-Mass Spectrometry (UPLC-ESI-QTOF-MS) to separate and quantify 10 chosen proteinaceous underivatized amino acids faster and at lower detection limits than published results up to date. To be noted Armstrong and coworkers [40] did not published the LOD and LOQ they obtained. We also present an application to natural samples of fluids from ultramafic-hosted hydrothermal vents and report the measured DFAA concentrations.

\section{Materials and Methods}

\subsection{Chemicals and Labware}

Amino acid standards were supplied by Merck. The ion pairing agent, heptafluorobutyric acid (HFBA) and HPLC grade acetonitrile were purchased from Sigma-Aldrich. Water was deionized on a Milli-Q system (Milli$\mathrm{Q}$ reagent water system, Molsheim, France) at $18.2 \mathrm{Mohm}$. All glassware used was oven combusted at $400^{\circ} \mathrm{C}$ for $4 \mathrm{~h}$.

\subsection{Standards}

The consideration of thermodynamic [3] [7], experimental e.g. [41]-[46] and field data e.g. [13] [14] [17] [47] [48] together with analytical issues (separation, response, retention...) guided the choice of the 10 proteinogenic amino acids that were investigated in the present study. A stock solution comprising of Glutamic acid (Glu), Alanine (Ala), Methionine (Met), Tryptophan (Trp), Proline (Pro), Glycine (Gly), Lysine (Lys), Tyrosine (Tyr), Phenylalanine (Phe) and Leucine (Leu) in Milli-Q water at a concentration of ca. $20 \mathrm{mg} \cdot \mathrm{L}^{-1}$ was prepared. The quantity of each amino acid was weighted on an accurate scale and exact concentrations were determined and are given in Table 1. Diluted solutions at 1000, 200, 20 and $2 \mu \mathrm{g} \cdot \mathrm{L}^{-1}$ (i.e. ppb) were prepared from this stock solution.

\subsection{Hydrothermal Fluids Samples}

Hydrothermal fluids were sampled in titanium syringes from the Logatchev and the Ashadze hydrothermal field by the ROV Victor 6000 during the SERPENTINE cruise in winter 2007 and from the Rainbow hydrothermal field by the manned submarine Nautile during MOMARDREAM-naut cruise in summer 2007. Both cruises were conducted by the French research institute for marine sciences, Ifremer. Samples were taken at the nose of smokers to avoid seawater mixing. The accuracy of the sampling was guided by real time records of the temperature within the chimneys. However, mixing occurred anyway to some extent. Based on the Mg concentration, the percentage of pure fluid can be calculated. Table 2 lists the samples used in this study and gives their general characteristics and the proportion of pure fluid. As soon as the fluids were recovered, $10 \mathrm{~mL}$ aliquots of the samples were transferred into glass tubes, frozen immediately at $-80^{\circ} \mathrm{C}$ and stored until analysis. Samples were not filtered to limit the risk of contamination and because of the possibility of cell lysis during pressure-filtration. $5 \mathrm{~mL}$ of each hydrothermal fluid sample were evaporated at room temperature under a gentle $\mathrm{N}_{2}$ flux and re-extracted in $100 \mu \mathrm{L}$ of Milli-Q water. The extracts were then transferred into V-shaped vials and let 
Table 1. Molecular weight (M), concentration (C) in the standard stock solution and retention time (Rt) of the amino acids analysed in this study. Additionally is given the $\mathrm{m} / \mathrm{z}$ ratio of the protonated parent ion $[\mathrm{M}+\mathrm{H}]^{+}$with which each amino acid was identified.

\begin{tabular}{ccccc}
\hline & $\mathbf{M}\left(\mathbf{g} \cdot \mathbf{m o l}^{-\mathbf{1}}\right)$ & $\mathbf{m} / \mathbf{z} \mathbf{~} \mathbf{M}+\mathbf{H}]^{+}$ & $\mathbf{C}\left(\mathbf{m g} \cdot \mathbf{L}^{-\mathbf{1}}\right)$ & \multicolumn{2}{c}{$\mathbf{R t}(\mathbf{m i n})$} \\
\hline GLU & 147.13 & 148.06 & 20.00 & 1.06 \\
ALA & 89.09 & 90.06 & 19.00 & 1.11 \\
MET & 149.21 & 150.06 & 20.00 & 3.44 \\
TRP & 204.23 & 205.1 & 22.00 & 4.27 \\
PRO & 115.13 & 116.07 & 21.00 & 0.93 \\
GLY & 75.07 & 76.05 & 19.50 & 3.31 \\
LYS & 146.19 & 147.11 & 21.00 & 3.51 \\
TYR & 181.19 & 182.08 & 19.50 & 3.85 \\
PHE & 165.19 & 166.09 & 21.00 & 3.77 \\
LEU & 131.17 & 132.1 & 19.00 & \\
\hline
\end{tabular}

Table 2. Hydrothermal fluids samples main features. As seawater mixing occurred to some extent, the \% of pure fluid is given in the "Fluid" column. The Pre-C column gives how much the samples were concentrated before analyses (in fold). Concentrations are given in $\mathrm{nM}$ and refer to the concentration in the natural hydrothermal fluid originally, before preconcentration. A cross stands for detected but not quantified and nd for not detected.

\begin{tabular}{|c|c|c|c|c|c|c|c|c|c|c|c|c|c|c|c|c|c|c|}
\hline \multirow[t]{2}{*}{ Sample name } & \multirow[t]{2}{*}{ Site } & \multirow{2}{*}{$\begin{array}{c}\text { Depth } \\
(\mathrm{m})\end{array}$} & \multirow{2}{*}{$\begin{array}{c}\mathbf{T} \\
\left({ }^{\circ} \mathrm{C}\right)\end{array}$} & \multirow[t]{2}{*}{ pH } & \multirow{2}{*}{$\begin{array}{c}\mathbf{C l}^{-} \\
\mathrm{mM}\end{array}$} & \multirow{2}{*}{$\begin{array}{c}\mathbf{H}_{\mathbf{2}} \\
\mathrm{mM}\end{array}$} & \multicolumn{4}{|c|}{ Fluid Pre-C } & \multicolumn{8}{|c|}{$\mathrm{C}$ in hydrothermal fluid (nM) } \\
\hline & & & & & & & $\%$ & fold & Glu & Ala & Met & $\operatorname{Trp}$ & Pro & Gly & Lys & Tyr & Phe & Leu \\
\hline MAD-D2-Ti2D & seawater & 2291 & 2 & 7.84 & 550 & - & 0 & 30 & nd & 3.86 & nd & nd & nd & nd & nd & nd & nd & $\mathrm{x}$ \\
\hline MAD-D3-Ti3G & Rainbow & 2307 & 350 & 3.23 & 761 & - & 97 & 25 & nd & nd & nd & $\mathrm{x}$ & nd & nd & nd & nd & nd & nd \\
\hline MAD-D6-Ti2G & Rainbow & 2265 & 353 & 3.41 & 711 & - & 73 & 40 & nd & nd & nd & nd & nd & nd & nd & nd & $\mathrm{x}$ & $\mathrm{x}$ \\
\hline MAD-D8-Ti1D & Rainbow & 2305 & 350 & 3.36 & 703 & - & 71 & 25 & nd & nd & nd & nd & $\mathrm{x}$ & nd & nd & nd & $\mathrm{x}$ & $\mathrm{x}$ \\
\hline SE-D2-Ti2 & Ashadze 1 & 4088 & 353 & 3.95 & 595 & 14.6 & 76 & 25 & nd & nd & nd & $\mathrm{x}$ & nd & nd & nd & nd & $\mathrm{x}$ & 0.41 \\
\hline SE-D2-Ti3 & Ashadze 1 & 4088 & 353 & 3.89 & 601 & 6.8 & 81 & 33 & nd & nd & nd & $\mathrm{x}$ & nd & nd & nd & nd & $\mathrm{x}$ & 0.11 \\
\hline SE-D6-Ti1 & Logatchev 1 & 3021 & 346 & 4.97 & 517 & 10.3 & 71 & 50 & nd & nd & nd & nd & nd & nd & nd & nd & $\mathrm{x}$ & $\mathrm{x}$ \\
\hline SE-D7-Ti1-L2 & Logatchev 2 & 2700 & 308 & 4.44 & 171 & 10.3 & 93 & 50 & nd & nd & nd & nd & nd & nd & nd & nd & $\mathrm{x}$ & $\mathrm{x}$ \\
\hline
\end{tabular}

sit until salts and precipitates would sediment. Finally, the supernatant was sampled with a glass Pasteur pipette, poured into an additional V-shaped vial and analysed. To be noted, only the DFAA will be detected with the current sample preparation approach.

\subsection{Analyses}

Amino acids were characterised by UPLC-ESI-QTOF-MS [49]. The ACQUITY UPLC ${ }^{\circledR}$ instrument (Waters, Milford, USA) coupled to a Micromass quadrupole time of flight (QTOF Premier) high resolution mass spectrometer (Waters, Manchester, UK). Compounds were separated on a BEH C $\mathrm{C}_{18} 1.7 \mu \mathrm{m}, 2.1 \times 50 \mathrm{~mm}$ column (Waters) at a flow rate of $250 \mu \mathrm{L} / \mathrm{min}$. Mobile phase A was a solution of $10 \mathrm{mM}$ HFBA in $(95 / 5)(\mathrm{v} / \mathrm{v})($ water/ acetonitrile) and mobile phase B was a solution of $10 \mathrm{mM} \mathrm{HFBA}$ in $(5 / 95)(\mathrm{v} / \mathrm{v})$ (water/acetonitrile). A gradient elution comprising of 7 steps was performed as follows: the mobile phases ratio (A:B) was (100:0) for 2 min; linear ramp to $(80: 20)$ in $0.5 \mathrm{~min}$ and held for $3 \mathrm{~min}$; linear ramp to $(0: 100)$ in $2 \mathrm{~min}$ and held for 3 min; linear ramp back to (100:0) in $0.5 \mathrm{~min}$ and held for $5 \mathrm{~min}$; which makes up the total run time to $16 \mathrm{~min}$. The mass spectrometer was operated in the positive ion mode and the MS parameters were set as follows: Capillary volt- 
age $3.0 \mathrm{kV}$, Sampling cone $25 \mathrm{~V}$, extraction cone $4 \mathrm{~V}$, source temperature $100^{\circ} \mathrm{C}$, desolvation temperature $350^{\circ} \mathrm{C}$ and collision energy 2.0. Automated injections were performed by the ACQUITY UPLC ${ }^{\circledR}$ Sample Manager. The protonated molecule $[\mathrm{M}+\mathrm{H}]^{+}$, of which the values of the mass to charge ratio $(\mathrm{m} / \mathrm{z})$ are given in Table 1 , was used as the selected ion for compound identification in a mass window of $0.05 \mathrm{Da}$. The selected amino acids were quantified using the manual integration feature of the MassLynxV4.1 software (Waters, Milford, MA, USA).

\subsection{Calibration}

Amino acids can be positively or negatively charged which allows the use of either a positive or a negative mode for MS detection. In the present study, ion-pairing agent HFBA was used as an additive in the mobile phase to enhance the retention of amino acids. HFBA is a strong acid, with a pKa value $<2$ which ensures all the amino acids to be protonated and therefore easily detected in positive mode. Also, the acidic HFBA will compete for charges with the amino acids in the ion-source and contribute to the overall ion-suppression in negative mode. In addition, amino acids are detected with higher sensitivities in the positive mode than in the negative mode [50]. The positive mode detection appeared thus most suitable. Finally, characterisation and retention of amino acids was confirmed by injection of $1000 \mathrm{ppb}$ standard solutions of each amino acid separately.

Calibration was designed to investigate linearity at lowest possible concentrations as amino acids were suspected to occur at levels $<1 \mathrm{nM}$ in natural samples [12] [14]-[16]. However, Gly was detectable only at relatively high concentration compared to the other amino acids and therefore two stronger concentrations were also injected for calibration which consists of the following injections: 2,4 and $10 \mu \mathrm{L}$ of the 2 ppb solution; 2, 4, 8 and $10 \mu \mathrm{L}$ of the $20 \mathrm{ppb}$ solution; $10 \mu \mathrm{L}$ of the 200 and $1000 \mathrm{ppb}$ solutions. The $1000 \mathrm{ppb}$ solution was also used as an external standard and was run on a regular basis over a day of analyses for control of retention times and peak intensity. Concentrations of the standards were normalised to a $10 \mu \mathrm{L}$ injected volume, so that linear ranges and LOD correspond to an injection of $10 \mu \mathrm{L}$. The linear ranges reported here have been restrained to the domain of concentrations of interest and therefore the upper limit of linearity should not be considered as the highest one. LOD were calculated and correspond to a signal to noise ratio $(\mathrm{S} / \mathrm{N})$ of 3 .

\section{Results and Discussion}

\subsection{Chromatography and Separation}

Several gradients, chromatographic conditions and ion-pairing agents were investigated before the optimum compromise was reached. Under these conditions (see Materials and Methods) the 10 amino acids investigated in the present work were easily detected and retained (see retention time [Rt] in Table 1). Separation was achieved in less than 4.5 min with very nice peak shapes (Figure 1); being about 3 times faster than with HPLC which is a common feature [35] [51]-[53]. This is also faster than other work using UPLC [33] [39] [40].

\subsection{Linearity and LOD}

All amino acids showed linear responses within 1 to 1.5 orders of magnitude with correlation coefficients $\left(r^{2}\right)$ higher than $>0.9921$ (Table 3). Glu, Met, Trp, Pro, Phe and Leu responses were linear from the sub-ppb to 10 $20 \mathrm{ppb}$ whereas Ala, Lys and Tyr showed a narrower range of linearity of 2 to $20 \mathrm{ppb}$ (Table 3). The response for Gly was also linear although in the much higher concentration range of 19.5 - 975 ppb which can be accounted for the little retention of the molecule which in turn may be due to the heavy charge and low molecular weight of Gly. LOD was down to the sub-ppb for most of the amino acids, Leu could even be detected at a concentration as low as $25 \mathrm{ppt}$. Ala and Lys could not be evidenced below the ppb and Gly was detected only from $20 \mathrm{ppb}$ (Table 3). Nevertheless, all these LOD are 1 to 4 orders of magnitude lower than the one reported to date with both similar and different analytical techniques measuring underivatized amino acids e.g. [26] [28] [29] [32] [34] [35] [39]. As a conclusion the method meets the expectations and the requirements in terms of time efficiency, linearity and low LOD.

\subsection{Reproducibility and Stability}

Reproducibility was found excellent and checked by doing three consecutive injections of the $1000 \mathrm{ppb}$ solution. This resulted in variation of less than $2 \%$ in Rt. Over a day of analyses, we observed a slight drift in the re- 


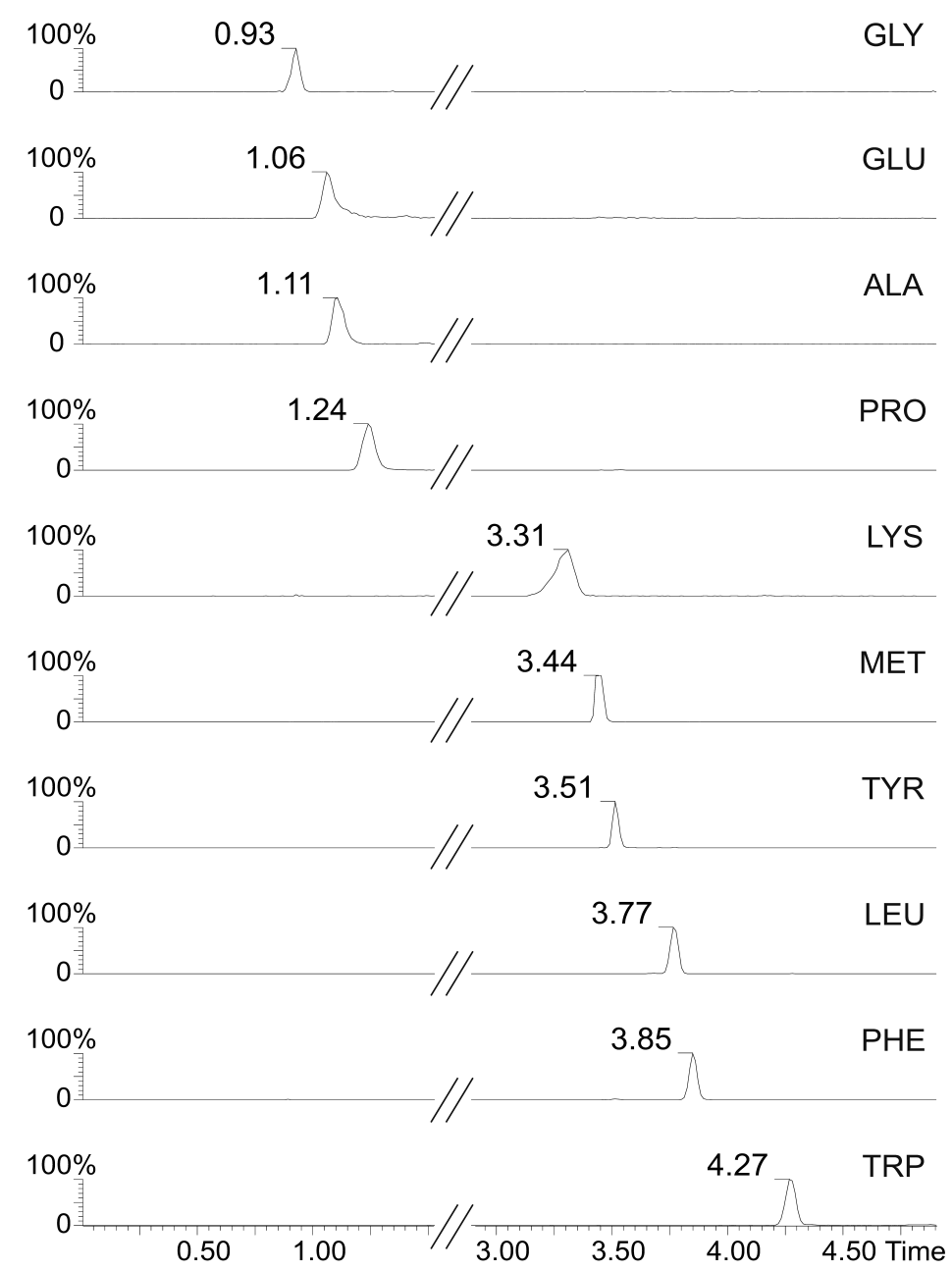

Figure 1. QTOF full SCAN of the 10 amino acids investigated in this study. The retention time Rt is indicated next to the amino acid peak. For clarity the $1.5-3.0$ min time zone has been cut off. $100 \%$ on the Y axis is $100 \%$ of the highest peak on the time and mass window chosen on the QTOF and does not represent a concentration.

Table 3. Linear regression equation, square correlation coefficients, linear ranges and LOD for each amino acids investigated in this study. Linear ranges and LOD refer to the concentration in the standard solution normalised to a $10 \mu \mathrm{L}$ injection.

\begin{tabular}{llcccc}
\hline & Equation & $\mathbf{r}^{2}$ & Linear range (ppb) & LOD (ppb) & LOD (nM) \\
\hline GLU & $y=0.0004 x+0.3042$ & 0.9991 & $0.8-16$ & 0.8 & 5.4 \\
ALA & $y=0.0001 x-0.0827$ & 0.9973 & $1.9-19$ & 1.5 & 16.8 \\
MET & $y=0.0003 x+0.3377$ & 0.9928 & $0.8-20$ & 0.53 & 3.6 \\
TRP & $y=0.0004 x+1.1147$ & 0.9967 & $0.44-17.6$ & 0.44 & 2.2 \\
PRO & $y=0.0007 x+0.1392$ & 0.9988 & $0.84-21$ & 0.84 & 7.3 \\
GLY & $y=3.00 \mathrm{E}-06 x+0.0890$ & 0.9982 & $19.5-975$ & 2.1 & 260 \\
LYS & $y=6.00 \mathrm{E}-05 x+0.3276$ & 0.9996 & $2.1-21$ & 0.39 & 14.3 \\
TYR & $y=0.0003 x+0.4718$ & 0.9966 & $1.95-15.6$ & 0.14 & 2.2 \\
PHE & $y=0.0013 x+3.6841$ & 0.9957 & $0.42-16.8$ & $25 \mathrm{ppt}$ & 0.8 \\
LEU & $y=0.0017 x+5.1268$ & 0.9948 & $0.38-15.2$ & 0.2 \\
\hline
\end{tabular}


tention of the compounds that appeared less retained, however variations in Rt were still good $(<13 \%)$. In addition, Rt were highly reproducible from day to day and even month to month. Indeed, twice two injection of the $1000 \mathrm{ppb}$ standard were done with one month interval and the obtained variation coefficients were less than $2 \%$.

\subsection{Application to Hydrothermal Fluids Samples-DFAA Measurements}

Four high temperature $\left(350^{\circ} \mathrm{C}-360^{\circ} \mathrm{C}\right)$, ultramafic-hosted hydrothermal systems located on the Mid-Atlantic Ridge were sampled: Rainbow $\left(36^{\circ} 13 \mathrm{~N}, 2300 \mathrm{~m}\right)$, Ashadze $1\left(12^{\circ} 58 \mathrm{~N}, 4100 \mathrm{~m}\right)$ and Logatchev 1 and $2\left(14^{\circ} 45 \mathrm{~N}\right.$, $2700-3000 \mathrm{~m}$ ). Details on geological settings and fluids inorganic geochemistry can be read in Charlou et al. [[10] and references therein]. All these sites are hosted on serpentinised peridotites with intrusive gabbroids and massive sulphides deposits are present extensively. Their fluids show the characteristic signature of hot fluids interacting with ultramafic rocks, i.e. high concentration in $\mathrm{H}_{2}$ and $\mathrm{CH}_{4}$, low silica contents, enriched in Li compared to basalt-hosted systems and depleted in B compare to surrounding seawater. Of particular interest are the highly reducing conditions observed due to the high amounts of $\mathrm{H}_{2}$ (Rainbow, $13-16 \mathrm{mM}$; Ashadze 18 - 19 mM; Logatchev 1.9 - 12.5 mM; Logatchev 2, $11 \mathrm{mM}$ ) [10]. However, each field exhibit a unique geochemistry and therefore every new discovered field or data on existing vents are crucial to better understand the overall hydrothermal biogeochemical processes.

The main characteristics of the hydrothermal fluids samples and the deep seawater reference sample that were analysed are given in Table 2. Deep seawater contained mainly Ala at a concentration of $3.86 \mathrm{nM}$ (A on Figure 2) and Leu was detected. Ala was also reported to be a major component of seawater [54] [55]. Gly could not be detected in any of the samples which we assume is due to its higher LOD. Although Glu, Lys and Tyr had a much lower LOD, they were not detected either in hydrothermal fluids, which means that they still might be present but at concentration below 5.4, 14.3 and $2.2 \mathrm{nM}$ respectively (Table 2 and Table 3). Pro possibly occurred in only one sample of the Rainbow field, however the peak area was very small, so this result will need to be confirmed by further analyses. All fluids from the Ashadze 1 vent contained Trp (C on Figure 2) as well as the purest hot fluid sample from the Rainbow field (97\% pure fluid) but was below LOQ. Phe could not be quantified in the samples as it was out of the linear domain, however it was definitely detected in all hydrothermal fluids (B on Figure 2) but one, whereas it was not detected in the deep seawater sample. Finally, Leu was with no doubt detected in all samples except for the purest hot fluid of the Rainbow field and measured concentrations were in the range 114 to $413 \mathrm{pM}$ (Table 2). Trp, Phe and Leu that were quite clearly evidenced in the samples showed linearity down to lower concentration than the other amino acids. Especially Leu, which had the highest response and lowest LOD, could be accurately quantified. To be noted, Isoleucine (Ile), an isomer of Leu, was not investigated in this series of experiments, nevertheless the injection at a later stage of a standard solution of Ile and a standard solution of Leu revealed that these compounds elute in two well resolved peaks separated by $10 \mathrm{~s}$. Therefore could Leu be distinguish from Ile and quantified separately.

We suspect amino acids to be present in hydrothermal fluids, however that a large portion occurs as metal complexes and cannot be detected using current approach. Earlier studies have shown indeed that amino acids can form complexes with a wide variety of metals and that the side chains $-\mathrm{OH},-\mathrm{COOH},-\mathrm{CONH}_{2}$ are often involved in the coordination [56] [57]. Notably, this phenomenon is not to be considered marginal as, for example, $\mathrm{Cu}^{\mathrm{II}}$ transport in blood partly occur via amino acid complexation [[58] and references therein]. Furthermore, the adsorption of amino acids on clay minerals is believed to occur through metal ions [59]. Besides, there is no doubt that clays [60], sand [61], sediments, [62] and many minerals [63]-[65] can retain and concentrate amino acids by adsorption. Mineral surface may also facilitate condensation and oligomerization reactions [66] although recent experiments under hydrothermal conditions led to the opposite conclusion [20]. Research regarding the adsorption and reactions of amino acids on mineral surfaces has largely been reviewed elsewhere [63] [66] [67]. As a result the amino acids possibly formed in hydrothermal systems may occur either adsorbed on minerals, or as oligomers or free; the proportion of each being unknown. The oligomer portion can be recovered and analysed by hydrolysis of the samples. Consistently Fuchida and coworkers found higher amounts of total hydrolizable amino acids (THAA) than DFAA in the Mariana Through [12]. Thus the very low concentration of DFAA detected in this study may represent only a small portion of the in-situ concentration. We suggest that a desalting step prior to preconcentration might help recovering higher amount of amino acids.

The amino acid concentration of our deep seawater reference is in the same order of magnitude as total DFAA background measured by other techniques in deep seawater from various places (Personal communication, R. 


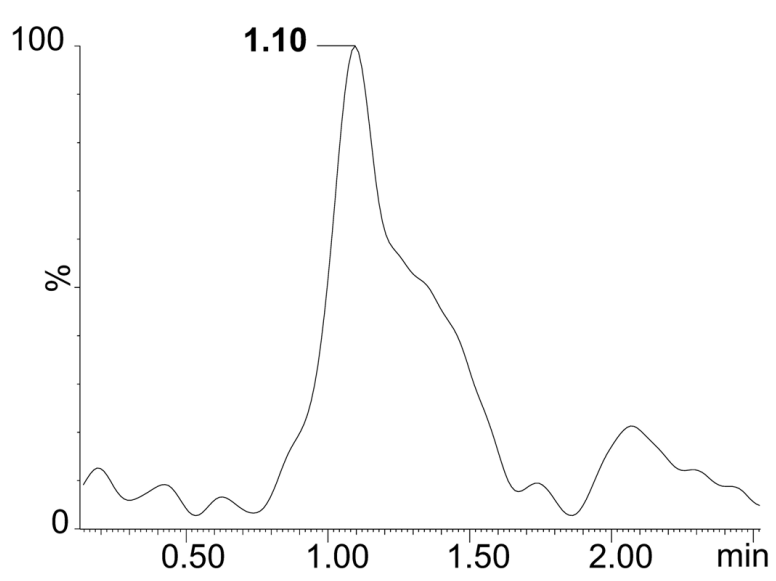

(A)

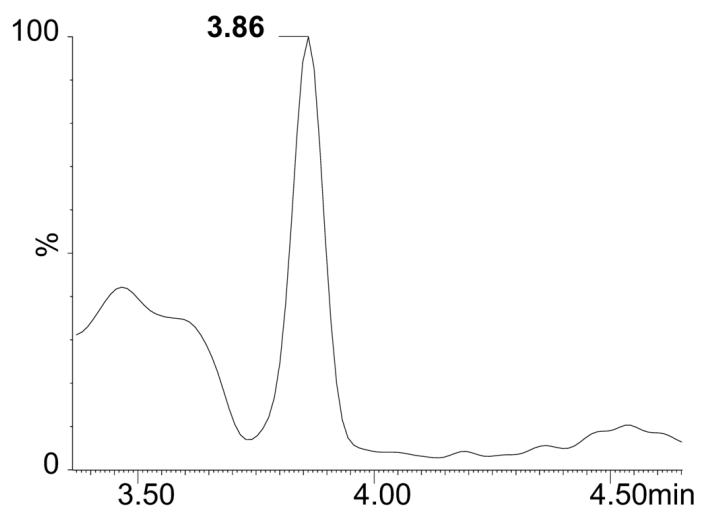

(B)

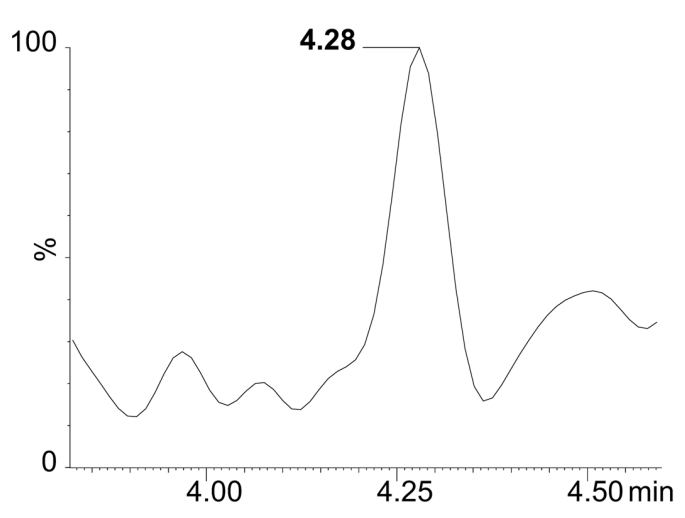

(C)

Figure 2. Representative parts of the QTOF full SCAN of three samples were selected and enlarged in order to show examples of amino acids peaks detected in the hydrothermal fluid samples. Ala in MAD-D2-Ti2D (A) could be quantified, whereas Phe and Trp in SE-D2-Ti2 (B and C respectively) could be detected but not quantified. $100 \%$ on the $\mathrm{Y}$ axis is $100 \%$ of the highest peak on the time and mass window chosen on the QTOF and does not represent a concentration.

Kerouel). It is also reasonably consistent with the concentrations $(<110 \mathrm{nM})$ reported by Kaiser [68] in the 2300 - $4000 \mathrm{~m}$ depth of the water column at a station in the Atlantic near Bermudas. Svensson et al. [17] have reported amino acids concentrations in a moderate temperature shallow hydrothermal system surrounded by sediments: Total DFAA values ranged from 330 to 78,380 nM for hydrothermal samples and $430 \mathrm{nM}$ for surrounding seawater. TDHFAA values published by Horiuchi et al. [14] for a deeper $(1380 \mathrm{~m})$ and hot $\left(300^{\circ} \mathrm{C}\right)$ hydrothermal system were in the lower range of $95.9-1061.6 \mathrm{nM}$ and $324 \mathrm{nM}$ for surrounding seawater. Amino acids contents were in the $3.82-15.24 \mu \mathrm{M}$ (THAA) and $<0.22 \mu \mathrm{M}$ (DFAA) in the hottest samples $\left(\mathrm{T}=160^{\circ} \mathrm{C}-\right.$ $270^{\circ} \mathrm{C}$ ) of a vent field located at $2800 \mathrm{~m}$ depth in the Mariana Through [12]. Only two studies report on the amino acid presence in ultramafic-hosted vents. Lost City $(\sim 800 \mathrm{~m}$ depth $)$ that is a one of its kind vent field having low $\mathrm{T}\left(<100^{\circ} \mathrm{C}\right)$ and very high $\mathrm{pH}(11)$ fluids has THAA concentrations ranging from $736-1565 \mathrm{nM}$ in the purest samples. Klevenz et al. [15] found very low total DFAA (38 nM) in their samples (fluid \% > 90) from the Logatchev ultramafic-hosted vent field whereas the other basalt-hosted fields of the Mid-Atlantic ridge had concentrations varying from 52 to $377 \mathrm{nM}$ in the samples containing more than $70 \%$ of fluid. All fields in their study lied by about $3000 \mathrm{~m}$ depth with a fluids temperature of $\sim 350^{\circ} \mathrm{C}$. We found here even lower amounts as only picomolar concentrations were measured. All fluids reached $350^{\circ} \mathrm{C}$ and were collected at depth between 2300 and $4000 \mathrm{~m}$. Our results complete the current dataset on amino acids in hydrothermal fluids but still no particular pattern relating amino acid concentration or occurrence with depth, temperature, host rocks or $\mathrm{pH}$ seems to emerge as mentioned by some of the above cited authors. This means that more work has to be done on natural samples to unravel the complex processes amino acids are involved in and to better understand their 
roles in hydrothermal environments and plumes. The technique we described here should help analysing more samples, faster, with low contamination source and down to sub-nM levels.

\section{Conclusion}

We report a method for the analyses of underivatized amino acids in the complex matrix that are hydrothermal fluids meaning low $\mathrm{pH}$, high salts and metal contents. The use UPLC-ESI-QTOF-MS ensures fast separation with high resolution. An ion-pairing agent (HFBA) was used to enhance the retention of amino acids on the apolar classic $\mathrm{C}_{18}$ column. Ten chosen proteinogenic amino acids were successfully separated in 4.5 min with symmetrical and thin peak shapes. The linearity was excellent for all amino acids and LOD were in the 0.2 $16.8 \mathrm{nM}$ range depending on amino acids at the exception of Gly $(260 \mathrm{nM})$. The method was found stable over days and months and exhibited a good reproducibility in Rt and peak areas. Overall the analyses of natural hydrothermal fluid samples were successfully carried out using our approach. The results are in agreement with published data for deep seawater and hydrothermal fluids. To be noted picomolar concentrations of Leu could be measured in 2 samples. Such low concentrations had never been reported in hydrothermal fluids because the LOD of other studies using other techniques were usually $\geq 1 \mathrm{nM}$.

\section{Acknowledgements}

We thank Yves Fouquet as well as Françoise Gaill and Jerôme Dyment chief scientists of the SERPENTINE (2007) and MOMARDREAM-naut1 (2007) cruises, respectively, who kindly allocated us a place to join their cruise and allowed us to collect and to use hydrothermal fluid samples for this study. We are also very thankful to IFREMER for funding and organisation of the cruises. Additionally, we particularly address our regards to the ROV Victor 6000 team, the Nautile team, the $R / V$ (Research Vessel) Pourquoi pas? crew and the $R / V$ $l$ 'Atalante crew for their time, efficiency and precious help. Also, we very much appreciated all discussions with Dr. R. Kerouel; they were very helpful and thank him for his time and for providing us with some data. This work has been carried out within the MoMARnet (Monitoring deep seafloor hydrothermal environments on the Mid-Atlantic Ridge: A Marie Curie Research Training network) framework that provided part of the research funding; the Swedish National Space Board provided with the rest of the funding.

\section{References}

[1] Corliss, J.B., Baross, J.A. and Hoffman, S.E. (1981) An Hypothesis Concerning the Relationship between Submarine Hot Springs and the Origin of Life on Earth. Proceedings 26th International Geological Congress, Oceanologica Acta, No SP, 59-69.

[2] Holm, N.G. (1992) Chapter 1 Why Are Hydrothermal Systems Proposed as Plausible Environments for the Origin of Life? Origins of Life and Evolution of Biospheres, 22, 5.

[3] Shock, E.L. (1992) Chapter 5 Chemical Environments of Submarine Hydrothermal Systems. Origins of Life and Evolution of Biospheres, 22, 67-107. http://dx.doi.org/10.1007/BF01808019

[4] Ferris, J.P. (1992) Chapter 6 Chemical Markers of Prebiotic Chemistry in Hydrothermal Systems. Origins of Life and Evolution of Biospheres, 22, 109-134.

[5] Macleod, G., McKeown, C., Hall, A.J. and Russell, M.J. (1994) Hydrothermal and Oceanic pH Conditions of Possible Relevance to the Origin of Life. Origins of Life and Evolution of Biospheres, 24, 19-41. http://dx.doi.org/10.1007/BF01582037

[6] Shock, E. and Canovas, P. (2010) The Potential for Abiotic Organic Synthesis and Biosynthesis at Seafloor Hydrothermal Systems, Blackwell Publishing Ltd., 161-192.

[7] Shock, E.L. (1990) Geochemical Constraints on the Origin of Organic Compounds in Hydrothermal Systems. Origins of Life and Evolution of Biospheres, 20, 331-367. http://dx.doi.org/10.1007/BF01808115

[8] Aubrey, A., Cleaves, H. and Bada, J. (2009) The Role of Submarine Hydrothermal Systems in the Synthesis of Amino Acids. Origins of Life and Evolution of Biospheres, 39, 91-108. http://dx.doi.org/10.1007/s11084-008-9153-2

[9] McCollom, T.M. (2013) Laboratory Simulations of Abiotic Hydrocarbon Formation in Earth's Deep Subsurface. Reviews in Mineralogy and Geochemistry, 75, 467-494. http://dx.doi.org/10.2138/rmg.2013.75.15

[10] Charlou, J.L., Donval, J.P., Konn, C., Ondreas, H., Fouquet, Y., Jean Baptiste, P. and Fourré, E. (2010) High Production and Fluxes of $\mathrm{H}_{2}$ and $\mathrm{CH}_{4}$ and Evidence of Abiotic Hydrocarbon Synthesis by Serpentinization in Ultramafic-Hosted Hydrothermal Systems on the Mid-Atlantic Ridge. In: Rona, P., Devey, C., Dyment, J. and Murton, B., Eds., 
Diversity of Hydrothermal Systems on Slow-Spreading Ocean Ridges, Washington DC, 265-296.

[11] Proskurowski, G., Lilley, M.D., Seewald, J.S., Fruh-Green, G.L., Olson, E.J., Lupton, J.E., Sylva, S.P. and Kelley, D.S. (2008) Abiogenic Hydrocarbon Production at Lost City Hydrothermal Field. Science, 319, 604-607. http://dx.doi.org/10.1126/science.1151194

[12] Fuchida, S., Mizuno, Y., Masuda, H., Toki, T. and Makita, H. (2014) Concentrations and Distributions of Amino Acids in Black and White Smoker Fluids at Temperatures over $200^{\circ}$ C. Organic Geochemistry, 66, 98-106. http://dx.doi.org/10.1016/j.orggeochem.2013.11.008

[13] Haberstroh, P.R. and Karl, D.M. (1989) Dissolved Free Amino Acids in Hydrothermal Vent Habitats of the Guaymas Basin. Geochimica et Cosmochimica Acta, 53, 2937-2945. http://dx.doi.org/10.1016/0016-7037(89)90170-1

[14] Horiuchi, T., Takano, Y., Ishibashi, J.I., Marumo, K., Urabe, T. and Kobayashi, K. (2004) Amino Acids in Water Samples from Deep Sea Hydrothermal Vents at Suiyo Seamount, Izu-Bonin Arc, Pacific Ocean. Organic Geochemistry, 35, 1121-1128. http://dx.doi.org/10.1016/j.orggeochem.2004.06.006

[15] Klevenz, V., Sumoondur, A., Ostertag-Henning, C. and Koschinsky, A. (2010) Concentrations and Distributions of Dissolved Amino Acids in Fluids from Mid-Atlantic Ridge Hydrothermal Vents. Geochemical Journal, 44, 387-397. http://dx.doi.org/10.2343/geochemj.1.0081

[16] Lang, S.Q., Früh-Green, G.L., Bernasconi, S.M. and Butterfield, D.A. (2013) Sources of Organic Nitrogen at the Serpentinite-Hosted Lost City Hydrothermal Field. Geobiology, 11, 154-169. http://dx.doi.org/10.1111/gbi.12026

[17] Svensson, E., Skoog, A. and Amend, J.P. (2004) Concentration and Distribution of Dissolved Amino Acids in a Shallow Hydrothermal System, Vulcano Island (Italy). Organic Geochemistry, 35, 1001-1014. http://dx.doi.org/10.1016/j.orggeochem.2004.05.005

[18] Lee, N., Foustoukos, D.I., Sverjensky, D.A., Cody, G.D. and Hazen, R.M. (2014) The Effects of Temperature, pH and Redox State on the Stability of Glutamic Acid in Hydrothermal Fluids. Geochimica et Cosmochimica Acta, 135, 66-86. http://dx.doi.org/10.1016/j.gca.2014.02.043

[19] Lee, N., Foustoukos, D.I., Sverjensky, D.A., Hazen, R.M. and Cody, G.D. (2014) Hydrogen Enhances the Stability of Glutamic Acid in Hydrothermal Environments. Chemical Geology, 386, 184-189.

http://dx.doi.org/10.1016/j.chemgeo.2014.08.012

[20] McCollom, T.M. (2013) The Influence of Minerals on Decomposition of the n-alkyl- $\alpha$-amino Acid Norvaline under Hydrothermal Conditions. Geochimica et Cosmochimica Acta, 104, 330-357. http://dx.doi.org/10.1016/j.gca.2012.11.008

[21] Cox, J.S. and Seward, T.M. (2007) The Reaction Kinetics of Alanine and Glycine under Hydrothermal Conditions. Geochimica et Cosmochimica Acta, 71, 2264-2284. http://dx.doi.org/10.1016/j.gca.2007.01.020

[22] Ito, M., Gupta, L.P., Masuda, H. and Kawahata, H. (2006) Thermal Stability of Amino Acids in Seafloor Sediment in Aqueous Solution at High Temperature. Organic Geochemistry, 37, 177-188. http://dx.doi.org/10.1016/j.orggeochem.2005.09.004

[23] Orsi, W.D., Edgcomb, V.P., Christman, G.D. and Biddle, J.F. (2013) Gene Expression in the Deep Biosphere. Nature, 499, 205-208. http://dx.doi.org/10.1038/nature12230

[24] Charlou, J.L., Donval, J.P., Fouquet, Y., Jean-Baptiste, P. and Holm, N. (2002) Geochemistry of High $\mathrm{H}_{2}$ and $\mathrm{CH}_{4}$ Vent Fluids Issuing from Ultramafic Rocks at the Rainbow Hydrothermal Field (36 14 'N, MAR). Chemical Geology, 191, 345-359. http://dx.doi.org/10.1016/S0009-2541(02)00134-1

[25] Charlou, J.L., Fouquet, Y., Bougault, H., Donval, J.P., Etoubleau, J., Jean-Baptiste, P., Dapoigny, A., Appriou, P. and Rona, P.A. (1998) Intense $\mathrm{CH}_{4}$ Plumes Generated by Serpentinization of Ultramafic Rocks at the Intersection of the $15^{\circ} 20^{\prime} \mathrm{N}$ Fracture Zone and the Mid-Atlantic Ridge. Geochimica et Cosmochimica Acta, 62, 2323-2333. http://dx.doi.org/10.1016/S0016-7037(98)00138-0

[26] Casella, I.G. and Contursi, M. (2003) Isocratic Ion Chromatographic Determination of Underivatized Amino Acids by Electrochemical Detection. Analytica Chimica Acta, 478, 179-189. http://dx.doi.org/10.1016/S0003-2670(02)01517-9

[27] Yu, H., Ding, Y.S., Mou, S.F., Jandik, P. and Cheng, J. (2002) Simultaneous Determination of Amino Acids and Carbohydrates by Anion-Exchange Chromatography with Integrated Pulsed Amperometric Detection. Journal of Chromatography A, 966, 89-97.

[28] Özcan, S. and Şenyuva, H.Z. (2006) Improved and Simplified Liquid Chromatography/Atmospheric Pressure Chemical Ionization Mass Spectrometry Method for the Analysis of Underivatized Free Amino Acids in Various Foods. Journal of Chromatography A, 1135, 179-185. http://dx.doi.org/10.1016/j.chroma.2006.09.039

[29] Yan, D., Li, G., Xiao, X.H., Dong, X.P. and Li, Z.L. (2007) Direct Determination of Fourteen Underivatized Amino Acids from Whitmania Pigra by Using Liquid Chromatography-Evaporative Light Scattering Detection. Journal of Chromatography A, 1138, 301-304. 
[30] Petritis, K., Elfakir, C. and Dreux, M. (2002) A Comparative Study of Commercial Liquid Chromatographic Detectors for the Analysis of Underivatized Amino Acids. Journal of Chromatography A, 961, 9-21. http://dx.doi.org/10.1016/S0021-9673(02)00377-1

[31] Buiarelli, F., Gallo, V., Di Filippo, P., Pomata, D. and Riccardi, C. (2013) Development of a Method for the Analysis of Underivatized Amino Acids by Liquid Chromatography/Tandem Mass Spectrometry: Application on Standard Reference Material 1649a (Urban Dust). Talanta, 115, 966-972. http://dx.doi.org/10.1016/j.talanta.2013.07.009

[32] Le, A., Ng, A., Kwan, T., Cusmano-Ozog, K. and Cowan, T.M. (2014) A Rapid, Sensitive Method for Quantitative Analysis of Underivatized Amino Acids by Liquid Chromatography-Tandem Mass Spectrometry (LC-MS/MS). Journal of Chromatography B, 944, 166-174. http://dx.doi.org/10.1016/j.jchromb.2013.11.017

[33] Zhou, G., Pang, H., Tang, Y., Yao, X., Mo, X., Zhu, S., Guo, S., Qian, D., Qian, Y., Su, S., Zhang, L., Jin, C., Qin, Y. and Duan, J.A. (2013) Hydrophilic Interaction Ultra-Performance Liquid Chromatography Coupled with TripleQuadrupole Tandem Mass Spectrometry for Highly Rapid and Sensitive Analysis of Underivatized Amino Acids in Functional Foods. Amino Acids, 44, 1293-1305. http://dx.doi.org/10.1007/s00726-013-1463-7

[34] Petritis, K., Chaimbault, P., Elfakir, C. and Dreux, M. (2000) Parameter Optimization for the Analysis of Underivatized Protein Amino Acids by Liquid Chromatography and Ionspray Tandem Mass Spectrometry. Journal of Chromatography A, 896, 253-263.

[35] Piraud, M., Vianey-Saban, C., Petritis, K., Elfakir, C., Steghens, J.P. and Bouchu, D. (2005) Ion-Pairing ReversedPhase Liquid Chromatography/Electrospray Ionization Mass Spectrometric Analysis of 76 Underivatized Amino Acids of Biological Interest: A New Tool for the Diagnosis of Inherited Disorders of Amino Acid Metabolism. Rapid Communications in Mass Spectrometry, 19, 1587-1602. http://dx.doi.org/10.1002/rcm.1957

[36] Chaimbault, P., Petritis, K., Elfakir, C. and Dreux, M. (1999) Determination of 20 Underivatized Proteinic Amino Acids by Ion-Pairing Chromatography and Pneumatically Assisted Electrospray Mass Spectrometry. Journal of Chromatography A, 855, 191-202. http://dx.doi.org/10.1016/S0021-9673(99)00685-8

[37] Liu, D.L., Beegle, L.W. and Kanik, I. (2008) Analysis of Underivatized Amino Acids in Geological Samples Using Ion-Pairing Liquid Chromatography and Electrospray Tandem Mass Spectrometry. Astrobiology, 8, 229-241. http://dx.doi.org/10.1089/ast.2007.0176

[38] Takano, Y., Chikaraishi, Y. and Ohkouchi, N. (2014) Isolation of Underivatized Amino Acids by Ion-Pair High Performance Liquid Chromatography for Precise Measurement of Nitrogen Isotopic Composition of Amino Acids: Development of Comprehensive LC $\times$ GC/C/IRMS Method. International Journal of Mass Spectrometry, In Press.

[39] Troise, A., Fiore, A., Roviello, G., Monti, S. and Fogliano, V. (2015) Simultaneous Quantification of Amino Acids and Amadori Products in Foods through Ion-Pairing Liquid Chromatography-High-Resolution Mass Spectrometry. Amino Acids, 47, 111-124. http://dx.doi.org/10.1007/s00726-014-1845-5

[40] Armstrong, M., Jonscher, K. and Reisdorph, N.A. (2007) Analysis of 25 Underivatized Amino Acids in Human Plasma Using Ion-Pairing Reversed-Phase Liquid Chromatography/Time-of-Flight Mass Spectrometry. Rapid Communications in Mass Spectrometry, 21, 2717-2726. http://dx.doi.org/10.1002/rcm.3124

[41] Bar-Nun, A., Bar-Nun, N., Bauer, S.H. and Sagan, C. (1970) Shock Synthesis of Amino Acids in Simulated Primitive Environments. Science, 168, 470-472. http://dx.doi.org/10.1126/science.168.3930.470

[42] Hennet, R.J.C., Holm, N.G. and Engel, M.H. (1992) Abiotic Synthesis of Amino Acids under Hydrothermal Conditions and the Origin of Life: A Perpetual Phenomenon? Naturwissenschaften, 79, 361-365.

http://dx.doi.org/10.1007/BF01140180

[43] Marshall, W.L. (1994) Hydrothermal Synthesis of Amino Acids. Geochimica et Cosmochimica Acta, 58, $2099-2106$. http://dx.doi.org/10.1016/0016-7037(94)90288-7

[44] Yanagawa, H. and Kobayashi, K. (1992) Chapter 8. An Experimental Approach to Chemical Evolution in Submarine Hydrothermal Systems. Origins of Life and Evolution of the Biosphere, 22, 147-159. http://dx.doi.org/10.1007/BF01808022

[45] Andersson, E. and Holm, N.G. (2000) The Stability of Some Selected Amino Acids under Attempted Redox Constrained Hydrothermal Conditions. Origins of Life and Evolution of the Biosphere, 30, 9-23. http://dx.doi.org/10.1023/A:1006668322298

[46] Islam, M.N., Kaneko, T. and Kobayashi, K. (2001) Determination of Amino Acids Formed in a Supercritical Water Flow Reactor Simulating Submarine Hydrothermal Systems. Analytical Sciences, 17, i1631-i1634.

[47] Managau, L.M. and Courtot, P. (1987) Dissolved Free Amino Acids of Coastal Seawater (Strait of Brest, France). Journal de Recherche Oceanographique, 12, 39-42.

[48] Henrichs, S.M., Farrington, J.W. and Lee, C. (1984) Peru Upwelling Region Sediments near 15 ${ }^{\circ}$ S. 2. Dissolved Free and Total Hydrolyzable Amino Acids. Limnology and Oceanography, 29, 20-34. 
http://dx.doi.org/10.4319/10.1984.29.1.0020

[49] Waters-Corporation (2009) ACQUITY UPLC® Systems - Overcome the Challenges of Analytical Laboratories. http://www.waters.com/webassets/cms/library/docs/720001507en.pdf

[50] Hiraoka, K., Murata, K. and Kudaka, I. (1995) Do the Electrospray Mass Spectra Reflect the Ion Concentrations in Sample Solution? Journal of the Mass Spectrometry Society of Japan, 43, 127-138. http://dx.doi.org/10.5702/massspec.43.127

[51] Houghton, R. and Grace, P. (2008) UHPLC - Why All the Hype? Chromatography Today, 5-7.

[52] Waters-Corporation (2004) New Quadrupole MS Detection Capabilities for Ultra Performance LC. http://www.waters.com/webassets/cms/library/docs/720001762en.pdf

[53] Waters-Corporation (2007) An Introduction to UPLC® Technology: Improve Productivity and Data Quality. http://www.waters.com/webassets/cms/library/docs/720002425en.pdf

[54] Sommerville, K. and Preston, T. (2001) Characterisation of Dissolved Combined Amino Acids in Marine Waters. Rapid Communications in Mass Spectrometry, 15, 1287-1290. http://dx.doi.org/10.1002/rcm.302

[55] Daumas, R.A. (1976) Variations of Particulate Proteins and Dissolved Amino Acids in Coastal Seawater. Marine Chemistry, 4, 225-242. http://dx.doi.org/10.1016/0304-4203(76)90010-4

[56] Farkas, E. and Sóvágó, I. (2002) Amino Acids, Peptides and Proteins. The Royal Society of Chemistry, London.

[57] Yamauchi, O. and Odani, A. (1996) Stability Constants of Metal Complexes of Amino Acids with Charged Side Chains - Part I: Positively Charged Side Chains. Pure and Applied Chemistry, 68, 469-496. http://dx.doi.org/10.1351/pac199668020469

[58] Evans, G.W. (1973) Copper Homeostasis in the Mammalian System. Physiological Reviews, 53, 535-570.

[59] Gupta, A., Loew, G.H. and Lawless, J. (1983) Interaction of Metal Ions and Amino Acids: Possible Mechanisms for the Adsorption of Amino Acids on Homoionic Smectite Clays. Inorganic Chemistry, 22, 111-120. http://dx.doi.org/10.1021/ic00143a025

[60] Hedges, J.I. and Hare, P.E. (1987) Amino Acid Adsorption by Clay Minerals in Distilled Water. Geochimica et Cosmochimica Acta, 51, 255-259. http://dx.doi.org/10.1016/0016-7037(87)90237-7

[61] Zaia, D.A.M., Vieira, H.J. and Zaia, C.T.B.V. (2002) Adsorption of L-Amino Acids on Sea Sand. Journal of the Brazilian Chemical Society, 13, 679-681. http://dx.doi.org/10.1590/S0103-50532002000500023

[62] Henrichs, S.M. and Sugai, S.F. (1993) Adsorption of Amino Acids and Glucose by Sediments of Resurrection Bay, Alaska, USA: Functional Group Effects. Geochimica et Cosmochimica Acta, 57, 823-835. http://dx.doi.org/10.1016/0016-7037(93)90171-R

[63] Zaia, D.A.M. (2004) A Review of Adsorption of Amino Acids on Minerals: Was It Important for Origin of Life? Amino Acids, 27, 113-118. http://dx.doi.org/10.1007/s00726-004-0106-4

[64] Holm, N.G., Dowler, M.J., Wadsten, T. and Arrhenius, G. (1983) $\beta$-FeOOH· $\mathrm{Cl}_{\mathrm{n}}$ (akaganéite) and $\mathrm{Fe}_{1-\mathrm{x}} \mathrm{O}$ (wüstite) in Hot Brine from the Atlantis II Deep (Red Sea) and the Uptake of Amino Acids by Synthetic $\beta$-FeOOH$\cdot \mathrm{Cl}_{\mathrm{n}}$. Geochimica et Cosmochimica Acta, 47, 1465-1470. http://dx.doi.org/10.1016/0016-7037(83)90305-8

[65] Hazen, R.M. and Sverjensky, D.A. (2010) Mineral Surfaces, Geochemical Complexities, and the Origins of Life. Cold Spring Harbor Perspectives in Biology, 2.

[66] Lahav, N. and Chang, S. (1976) The Possible Role of Solid Surface Area in Condensation Reactions during Chemical Evolution: Reevaluation. Journal of Molecular Evolution, 8, 357-380. http://dx.doi.org/10.1007/BF01739261

[67] Lambert, J.F. (2008) Adsorption and Polymerization of Amino Acids on Mineral Surfaces: A Review. Origins of Life and Evolution of Biospheres, 38, 211-242. http://dx.doi.org/10.1007/s11084-008-9128-3

[68] Kaiser, K. and Benner, R. (2009) Biochemical Composition and Size Distribution of Organic Matter at the Pacific and Atlantic Time-Series Stations. Marine Chemistry, 113, 63-77. 